\title{
A RATIONALIZED APPROACH TO THERMIONIC RF GUN DESIGN*
}

\author{
Kevin J. Beczek ${ }^{\dagger}$, John W. Lewellen, A. Nassiri \\ Advanced Photon Source, Argonne National Laboratory, \\ 9700 South Cass Avenue, Argonne, IL 60439 USA \\ Eiji Tanabe \\ Advanced Electronics Technologies Associates, Inc., \\ 20370 Town Center Lane, Cupertino, CA 95014 USA
}

\begin{abstract}
The Advanced Photon Source (APS), in conjunction with Advanced Electronics Technologies Associates (AET), is developing newly designed thermionic-cathode rf guns to replace our aging (circa 1992) guns. Each of the three third-generation injectors will meet or exceed the present high-performance electron beam of its secondgeneration predecessor. Moreover, the new injector design addresses the historical difficulties of maintenance, reliability, and sparse documentation associated with the previous injectors. Engineering design improvements and required performance of the guns will be presented following a brief examination of the APS secondgeneration guns for comparison.
\end{abstract}

\section{INTRODUCTION}

As a product emerges from infancy in the laboratory and matures on the production floor, lessons learned from previous experiences, both good and bad, are frequently incorporated as design modifications. The result of this successive iterative growth is a genuinely improved product. Indeed, it is through this rationalized approach that the third-generation (3G) rf guns were born. Prior to the arrival of these injectors, the APS was using one firstgeneration $(1 \mathrm{G})$ and one second-generation $(2 \mathrm{G}) \mathrm{rf}$ gun. Each alternated in the role of main injector and hot spare for reliable storage ring injection [1]. Both provided consistent and sufficient beam for our needs over the years they have been in service. However, a number of developments that occurred within the past year motivated us to procure a set of three state-of-the-art rf guns and to retire our present injectors. This also provided an ideal opportunity to redesign a few key features that had been troublesome in years past. Presentations on the physics and performance of the $1 \mathrm{G}$ and $2 \mathrm{G}$ S-band rf guns can be found in $[2,3,4]$.

\section{MOTIVATION}

\subsection{Interchangeability}

During the fall of 2000, plans to build an injector testing facility at APS were well underway [5]. We designed this facility to include an rf gun identical to the

\footnotetext{
*Work supported by the U.S. Department of Energy, Office of Basic Energy Sciences, under Contract No. W-31-109-ENG-38.

†beczek@aps.anl.gov
}

two that would be used in the linac. Of the two linac injectors, one would be the primary injector for APS, and the second would serve as a hot spare. From an engineering standpoint, it is quite advantageous that each injector in this triad be identical. It ensures reliable service to our beamline users by reducing the time and effort involved in maintenance and training, and streamlines logistics and procurement of spare parts. Moreover, we can effectively validate experimental equipment, such as new diagnostics, in a beamline completely independent of the linac.

\subsection{Maintenance}

The oxygen-free high-conductivity (OFHC) copper hulls of both rf guns are quite robust and conceivably will keep their integrity for many years to come. The cathode assembly, on the other hand, is more subject to the rigors of time and use and as such is a strong candidate for improvement. The two present rf guns use a removable 6mm-diameter thermionic dispenser cathode assembly of late 1980s vintage. They have performed fairly well, but several issues came to our attention during the year 2000 operations periods. First, our supply of cathode assemblies was nearly exhausted. Moreover, this product was no longer a current production item of Communications and Power Industries (formerly a division of Varian Associates) [6]. The manufacturer informed us that they could indeed fabricate the highvoltage feedthrough, a major component of the cathode assembly, albeit only on a batch basis. Second, the cathode assemblies that we did have were showing a marked decrease in performance compared with those used in past years. One untested hypothesis states that oxygen from the atmosphere was slowly permeating the nitrogen-purged cathode assembly package, tainting the contents over the years without our knowledge. Unfortunately, these packages, which were made from thin sheets of Mylar [7] foil, did not have an expiration date on them. Furthermore, the most recent cathode assembly had a manufacture date of 1992 .

In addition to the availability issues, the design of the cathode proper and cathode mount is not only difficult to work on, but quite tedious to remove and install. This point was painfully obvious to the technicians who had to service the $1 \mathrm{G}$ and $2 \mathrm{G}$ guns. In fact, many of the features 
on the $3 \mathrm{G}$ guns were the result of our listening to the suggestions of these technicians.

\subsection{Lack of Documentation}

One of the more frustrating aspects of maintaining the present injectors is the lack of accurate documentation. A tremendous number of man hours were spent researching work that was done over a decade ago. To some extent this could be blamed on the fact that the guns were originally intended to be used for research purposes rather than as main synchrotron injectors so far into the future. After this experience, we decided to make accurate blueprints and cathode conditioning procedures an absolute necessity.

\section{PERFORMANCE REQUIREMENTS}

The following is an abbreviated list of the physical and performance requirements of the $3 \mathrm{G}$ rf guns as submitted to AET Associates:

- 2 cells, one full cell and 0.6 cathode cell

- $\quad$ rf power feed on the full cell, with power transferred to the cathode cell by a side-coupled cavity

- 6-mm-diameter thermionic cathode

- field profile identical to APS second-generation rf gun

- resonant frequency $2856.0+/-0.1 \mathrm{MHz}$ at 40.8 deg. C in vacuum

- $\quad$ quality factor of 11000 minimum, corresponding to an externally measured FWHM resonance line width of approximately $1.2 \mathrm{MHz}$

- rf coupling: overcoupled cold, $=2.5+/-0.2$

- nominal micropulse duration: 1.5 microseconds

- accelerating gradients:

o full cell: $70 \mathrm{MV} / \mathrm{m}$ peak on-axis field after conditioning

- peak on-axis field strength ratios, cathode to full cell: $1: 1.63$

- $\quad$ field probes for cathode and full cells (may be placed on pump out ports)

- removable cathode holder/heat dam for 6-mm cathode

- $\quad$ one pump-out port per cell

- vacuum better than $5 \times 10^{-9}$ Torr after bakeout (heater cold, no rf power applied)

- Merdinian crush-seal (also known as SLAC type; not Scarpass) vacuum waveguide flanges on high-power rf feed

- 2-3/4" Conflat flanges on beam output port and all pump-out ports

- 1-1/3" Conflat flange on heater feedthrough port and on all $\mathrm{rf}$ probe ports

- 4-5/8" Conflat flange on cathode access port

- cooling capacity sufficient to maintain gun in resonance under the following conditions: o rf power into the gun sufficient to generate 70 $\mathrm{MV} / \mathrm{m}$ peak on-axis field in full cell

○ $10-\mathrm{Hz}$ macropulse repetition rate

- 1.5- $\mu$ s macropulse duration

○ 1.0-A beam current (at end of macropulse)

- cathode plane to center of full cell $5.848+0.1 /-0.0 \mathrm{~cm}$

- cell alignment concentricity: $0.05 \mathrm{~mm}$

The overall size and shape of the $3 \mathrm{G}$ guns had to conform to the spatial envelope of the preceding guns. To elaborate, the location of the rf power feed with respect to the beamline axis and the distance between the front vacuum flange and the rear vacuum flange had to be the same so that it would be interchangeable with the firstand second-generation rf guns in the GTL transport line. The notion of vacuum ports mounted on each side of the gun body was considered highly desirable by our technicians, but this was eventually dropped because of cell asymmetry, i.e., the rf power feed was at the 12 o'clock position, so a port had to be placed at the 6 o'clock position to balance the electric field profile [8].

\section{DESIGN IMPROVEMENTS}

\subsection{Cathode Assembly}

By far one of the most significant improvements has been the cathode assembly. The assemblies used on both of the $1 \mathrm{G}$ and $2 \mathrm{G}$ guns are more complicated and, evidently, more time consuming to put into operation. The device can be divided into four components: high-voltage feedthrough, heat dam, cathode stem, and a tungsten wire spring that functions as an rf choke. The skill of an experienced technician was required to assemble all of the aforesaid parts in a clean room to, in at least one operation, micron-level accuracy. AET and Heatwave Labs [9] have vastly simplified this complicated arrangement by designing the aforesaid parts into a neat and compact package that is preassembled at the factory and doesn't require the delicate touch of an expert technician.

\subsection{Field Probe Port Locations}

The present rf guns are supported at the front and rear flanges via a cradle, consisting of two v-blocks in series that provides for adjustment of yaw pitch, and roll. This has proven to be a satisfactorily rigid and thoroughly tested mechanism for ease of alignment. However, the field probe ports of the guns are located near the bottom of the gun body, making them very difficult or impossible to access for adjustments. In order to keep this cradle interchangeable between the entire support structure of the gun to linac (GTL) transport line and the injector test stand, we decided to switch the field probe port locations to as near the top of the gun body as possible, rather than modify the cradle. 


\section{COMMISSIONING RESULTS}

Literally at the time of writing, the first of the new $3 \mathrm{G}$ guns has undergone commissioning tests and is demonstrating outstanding performance. At a pulse length of $1.0 \mu$ s (identical to APS operations), we have measured $400 \mathrm{~mA}$ peak beam current at the end of the rf pulse and $5 \mathrm{MW}$ input rf power. This is an increase of $150 \%$ and $20 \%$, respectively, over operational levels from our $1 \mathrm{G}$ and $2 \mathrm{G}$ rf guns. The total "clock" time was about 3.5 hours from the start of conditioning to achieving these performance levels. All operationally based acceptance criteria have been exceeded substantially, and we have met or exceeded most of our conditioning goals. We are, therefore, anticipating a long and productive service life for our new excellently designed and manufactured injectors. Installation of the first third-generation gun is scheduled for the July 2001 maintenance period, and the balance of two guns will follow very shortly thereafter. A Pro/Engineer [10] solid model of the $3 \mathrm{G}$ rf gun sitting in the cradle is shown in Figure 1.

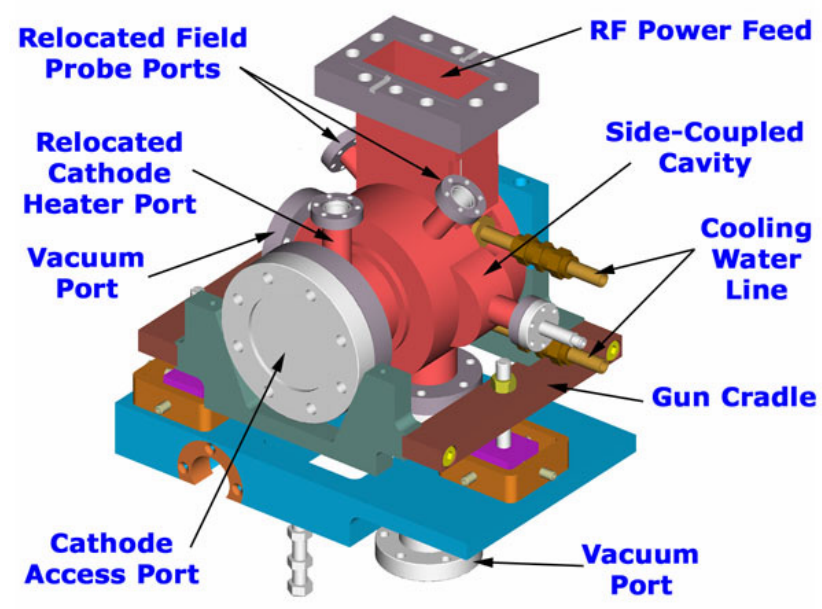

Figure 1: APS third-generation thermionic rf gun.

\section{ACKNOWLEDGEMENTS}

We would like to thank the staff of Nihon Koshuha [11] and especially Dr. Atsushi Miura for his dedication to manufacturing a quality product.

\section{REFERENCES}

[1] J. Lewellen et al., "A Hot Spare Injector for the APS Linac,” Proc. 1999 Linear IEEE Part. Accel. Conf., New York, 1979 (1999).

[2] E. Tanabe et al., "A 2-MeV Microwave Thermionic Gun," SLAC-PUB-5054, August 1989; presented at $14^{\text {th }}$ Meeting on Linear Accelerators, Nara, Japan (1989).

[3] J. Lewellen et al., "Operation of the APS RF Gun," Proc. 1998 Linear Accel. Conf., Chicago, 863 (1998).

[4] M. Borland et al., "Performance of the $2-\mathrm{MeV}$ Microwave Gun for the SSRL $150 \mathrm{MeV}$ Linac," SLAC-PUB-5333, September 1990; presented at the Linear Accelerator Conference, Albuquerque, New Mexico (1990).

[5] J. Lewellen et al., "The APS Injector Test Stand," these proceedings.

[6] Communications and Power Industries, Palo Alto, California USA.

[7] Mylar brand polyester film is a registered trademark of E.I. du Pont de Nemours and Company, Wilmington, DE 19898 USA.

[8] E. Tanabe, et al., "A Novel Structure of Multipurpose RF Gun,” Proc. 1998 Linear Accel. Conf., Chicago, 162 (1998).

[9] Heatwave Labs, Inc., 310 Emerald City Way, Watsonville, CA 95076 USA.

[10] Pro/Engineer is a registered trademark of Parametric Technology Inc., Waltham, MA USA.

[11] Nihon Koshuha Co., Ltd. 1119, Nakayama-cho, Midori-ku, Yokohama 226-0011, Japan. 